\title{
- IA educación para la paz en el CONTEXTO DE LA COMPLEMENTACIÓN DE PARADIGMAS Y LA POSTMODERNIDAD
}

\author{
Alfonso Fernández Herrería \\ Universidad de Granada
}

Desde hace una década y, especialmente en los últimos años, las publicaciones sobre la temática de las transversales y, concretamente, sobre la educación para la paz (en adelante EpP) han sido cada vez más numerosas. Sin embargo hay aspectos de la EpP que han sido insuficientemente tratados, como el de sus diferentes modelos. Así, por ejemplo, en los pocos casos en que se relaciona la EpP con las tres grandes tradiciones o paradigmas de racionalidad de las ciencias sociales (técnico-positivista, hermenéutico-cultural y el socio-crítico o comunicativo), se la incluye dentro del modelo crítico pero percibido como opuesto a los otros. Este tipo de percepciones trasladan todos los defectos de la interpretación de las tradiciones como opuestas entre sí al campo de la EpP. Reconociendo el hecho de que en una etapa anterior (años ochenta) se acentuaba las oposiciones entre los diferentes paradigmas, hoy día tenemos que desecharlas pues desde hace años se aboga ya por el encuentro y complementación de perspectivas. Es lógico, entonces, que nos preguntemos qué significa ahora la EpP desde una perspectiva crítica en un contexto de complementación de paradigmas, lo que supone situar a la EpP en los procesos de cambio de estas tradiciones, ver cómo le afectan, lo que incluye su relación con la modernidad y la postmodernidad. Así, bajo la expresión "teoría crítica", por ejemplo, tenemos movimientos muy dispares: lo que se llama la nueva sociología de la educación, la teoría crítica de Francfort, los análisis neomarxistas, el movimiento reconceptualizador del currículum (que ya de por si es muy amplio) entre otros. Estas corrientes, además 
de estar cambiando en parte por el juego cruzado de las críticas de unos a otros, en muchos casos se solapan entre sí o hacen crisis en diversos aspectos en su choque con las posturas postmodernas. Todo esto muestra la necesidad de que la EpP dialogue con estas corrientes en este marco complejo, lo que sin duda comportará enriquecimiento, matizaciones y posturas más cautelosas que nos permitirá diseñar grandes líneas en las que contextualizar la respuesta a la cuestión acerca de qué pueda entenderse hoy por EpP desde la perspectiva crítica.

\section{LA POLÉMICA GADAMER-HABERMAS. IMPLICACIONES EN LA EpP}

Para Heidegger sólo es el Dasein (el-estar-ahí-del hombre, que designa tanto la relación del ser a la esencia del hombre, como la relación esencial del hombre a la apertura -Da- del ser-Sein-) el único ente que puede plantearse la pregunta por el ser y ello es porque ya tiene un pre-juicio de lo que es el ser. De lo que se trata ahora es de explicitar ese pre-juicio, de liberar esa experiencia natural misma como mera cotidianidad donde está ya dada la totalidad del ser del hombre. G. Vattimo (1987, 103-104) lo expresa así:

Ser en el mundo (...) significa estar ya familiarizado con una totalidad de significaciones, con un contexto de referencias (...). Esta familiaridad preliminar con el mundo, que se identifica con la existencia misma del Dasein, es lo que Heidegger llama comprensión o precomprensión. Todo acto de conocimiento no es más que una articulación, una interpretación de esta familiaridad preliminar con el mundo.

La fenomenología hermenéutica de Heidegger busca liberar esa experiencia premetafísica del ser, esa familiaridad que se desvela en el hombre. Desde esta perspectiva, se entiende que para Gadamer y también para Ricoeur, la hermenéutica, no es sólo un problema metodológico del campo de las ciencias humanas, sino un modo (ontológico) de comprender nuestra situación en el mundo (Bolívar, 1995, 60-61). Por eso Gadamer habla de «distanciamiento alienante» (nada más alienante que buscar separarse de nuestra radicalidad de ser-en-el-mundo) para referirse a la separación del sujeto respecto del objeto buscada por la metodología positivista como exigencia de objetividad. Para la hermenéutica de Gadamer, la liberación o recuperación de esa experiencia perdida u olvidada supone captar las condiciones existenciales de la misma posibilidad de comprender. Esto se consigue porque los actos del sujeto están situados en una tradición y, por tanto, en la historia, por eso la comprensión se da necesariamente dentro de una tradición (al formar parte de ella esos pre-juicios) a la que pertenecemos por nuestra radical historicidad como seres-en-el-mundo. Esos pre-juicios es esa precomprensión en la que toda comprensión se halla situada. El sujeto no puede evadir su propio contexto histórico que condiciona su situación hermenéutica. Aquí aparece 
ese "círculo hermenéutico" pues el intérprete está necesariamente implicado en la tradición interpretada. Justo con estas ideas nos encontramos en el centro del debate entre Gadamer (hermenéutica) y Habermas (crítica de las ideologías) que fue muy intenso en los años sesenta y setenta y en el que han mediado, entre otros, K. Apel y Ricoeur, pues para Gadamer estamos situados, limitados, condicionados, sometidos a prejuicios... en definitiva, inmersos en tradiciones y no cabe una posición crítica pues esta necesitaría partir de una situación privilegiada. Habermas reconoce el mérito de la hermenéutica como enfoque para las ciencias sociales, pero sostiene que la reflexión puede hacer más que conocer el hecho condicionante de las tradiciones, puede intentar transformarlo.

Lo que se plantea al enfoque interpretativo es si debe limitarse a un acto de registro y descripción fenomenológica de lo que observa y de las autoconcepciones expresadas por los que viven la situación o puede plantear alternativas críticas. La crítica de Habermas a la hermenéutica de que perpetúa los pre-juicios heredados, las tradiciones, nos parece correcta. La teoría crítica asume el reto hermenéutico pero se propone completarlo. Podemos conocer los hechos desde una perspectiva hermenéutica pero también podemos cambiarlos, de ahí que haya una recuperación de la hermenéutica desde el enfoque crítico. En este sentido ambas corrientes pueden verse como complementarias pues podemos tomar conciencia de nuestros condicionamientos y así superarlos desde una crítica de las ideologías. Así pues, reconociendo el papel de la tradición y de los condicionamientos históricos en toda interpretación, eso no significa que debamos aceptar esos condicionamientos contextuales sin crítica alguna, pues sería tanto como admitir que los prejuicios tienen prioridad sobre la reflexión. Debe ser ésta la que muestre los posibles intereses implícitos de las tradiciones y condicionamientos de tal forma que en vez de ver desde ellos, los veamos a ellos. Esta "separación» u objetivación de los propios condicionamientos o tradiciones recibidas es la capacidad, el poder que configura la crítica de las ideologías. Pero claro está, como replica Gadamer a Habermas, no podemos ser dogmáticos y tenemos que admitir que la misma crítica se hace desde una posición y, por tanto, no escaparía a una determinada situación histórica. No cabe una posición supracontextual, es cierto, pero tampoco podemos dejarnos arrastrar a la posición de extremo relativismo del "todo vale» propia de aquél que razonara así: puesto que no hay posiciones privilegiadas o supracontextuales, estando todas situadas, serían inconmensurables entre sí (incomparables) al no poder existir patrones privilegiados con los que compararse.

En el ámbito de las Ciencias de la Educación el debate entre la hermenéutica y la crítica tiene posiciones reconocibles. En realidad las críticas tanto de Elliot (1987) contra el movimiento crítico, como las de Carr y Kemmis (1988) contra la hermenéutica reproducen las mismas posturas del debate Gadamer-Habermas: no es suficiente una teoría educativa basada en las propias interpretaciones de los enseñantes, en sus auto-entendimientos como enseñantes, sino que también se debe estar dispuestos a evaluarlas críticamente a 
fin de que, en función de necesarios criterios normativos, discriminar qué teorías personales son más adecuadas o válidas y así indicar líneas de acción alternativas, ya que no podríamos admitir como justificables todas las teorías prácticas de los profesores, sólo por el mero hecho de serlo, pues como dijimos eso nos llevaría al "todo vale», lo que supondría perpetuar situaciones. Esta es la posición de Carr y Kemmis. En consecuencia, más allá de toda oposición basada en análisis superficiales o en lealtades ideológicas, tenemos que reconocer la necesaria complementariedad de posiciones que, en el ámbito educativo, va más allá y acoge también al interés técnico propio de la metodología positivista. En este caso, no hay porqué asumir las posiciones ontológicas de la tradición positivista, ni tampoco sus posiciones epistemológicas. Podemos asumir sólo su metodología cuantitativa cuando su uso sea oportuno, viéndola como complementaria con la cualitativa. Esta mediación entre explicación científica y comprensión hermenéutica se complementa, como hemos visto hasta aquí, con la crítica de las ideologías. Esta sería la posición de K. Apel (1985, I), que como dijimos, entró en la polémica Gadamer-Habermas. K. Apel (1985, II, 119) sostiene que:

Surge la exigencia metodológica de mediar dialécticamente la 'explicación' de las ciencias sociales (empíricas) con la 'comprensión' de las ciencias histórico-hermenéuticas, bajo un principio regulativo: 'superar' los momentos irracionales de nuestra existencia histórica (...) denominamos 'crítica de las ideologías' al 'término técnico' de esta mediación dialéctica entre 'comprensión' y 'explicación'.

Todo lo expuesto hasta aquí es trasladable y aplicable al ámbito de la EpP.:

1.1. Si ya resulta simplista, cuando no erróneo, esos cuadros de oposición mutua entre las tres tradiciones, en la que toda postura posible puede ser catalogada bajo cada una de esos paradigmas, aún resulta más simplista aplicada al ámbito de la EpP, pues su desarrollo ha sido mayor en el campo de la práctica que en el de la discusión teórica paradigmática, y es precisamente en aquél, en el de la práctica, en donde se ha manifestado de hecho un alto nivel de complementación de perspectivas.

1.2. Asumir la oposición de las distintas tradiciones en el campo de la EpP como irreconciliables, además de que impediría dar cabal cuenta de toda la riqueza del hecho educativo, iría en contra de la secular sensibilidad que en el campo de la paz se tiene por la negociación, el diálogo y búsqueda de consensos.

3.1. Desde esta posición reconstructiva de complementación para el ámbito de la EpP, se asume, por tanto, el estudio de conductas y acciones que pudiendo ser eventualmente enfocadas desde metodologías cuantitativas, necesitarían ser descritas en un segundo 
momento desde perspectivas significativas, buscando la comprensión de esas conductas (investigación etnográfica) pero sin mitificar la descripción etnográfica como un absoluto, sin sacralizar lo personal y situacional (el conocimiento práctico personal), de tal forma que impidiera una visión crítica que buscara desvelar los condicionamientos ideológicos, sociales, los elementos irracionales... que se esconden en lo personal, en un momento posterior. Lo realmente significativo, dentro o fuera del aula, es que no nos quedemos sólo en conocer, en comprender, sino que debemos buscar la transformación emancipadora, liberadora, en consonancia con los valores de una cultura de paz.

Además de la comentada tendencia al diálogo de perspectivas, otra muy importante se ha configurado años atrás y ha tenido un hito simbólico significativo en la caída del muro de Berlín a finales de 1989. Me refiero a la crisis de la tradición crítica, especialmente en su versión neomarxista, y su reaparición en movimientos postestructurales y postmodernos que plantean redefinir la tradicional visión de la emancipación (Lather, 1992).

\section{CRISIS DE LA TRADICIÓN CRÍTICA Y MOVIMIENTOS POSTESTRUCTURALES Y POSTMODERNOS. EL TEMA DE LA EpP}

Ante el desengaño de las viejas certezas revolucionarias puestas en la clase obrera como sujeto de la revolución, la tradición crítica, antes inspirada principalmente en el marxismo, ha centrado su esperanza en otros movimientos (ecologismo, pacifismo, feminismo...).

\subsection{EVOLUCIÓN DEL MOVIMIENTO CRÍTICO Y SUS RELACIONES CON LA EpP}

Pinar y Bowers (1992) han hecho una revisión del movimiento crítico en el que se puede distinguir tres momentos o periodos:

Primer perfodo: es el marcado por la teoría de la reproducción (años setenta). El análisis marxista de la institución escolar se articula directamente con el análisis del Estado y con la lucha de clases, por lo que se ve a la escuela como reproductora de las estructuras de clase de la sociedad y, por tanto, de las desigualdades sociales que esconden las relaciones de producción capitalista en provecho de la clase dominante. Las conocidas obras de Bourdieu y Passeron, Baudelot y Establet, de Bowles y Gintis y gran parte de la obra de Bernstein están dentro de esta concepción mecanicista, economicista, funcionalista, reduccionista y estructuralista en la que al subrayar tanto la reproducción cultural, social y económica (violencias simbólicas y estructu- 
ral, en términos de teoría de la paz) eliminan la posibilidad de conflictos internos emancipadores en el seno de las instituciones, en este caso, la escolar. La inexorable fuerza condicionante de la infraestructura no dejaría espacio alguno para una intervención crítica en la realidad, para acciones contra hegemónicas, para una resistencia crítica y creativa (Fdez. Herrería, 1994, 185-202). Esta concepción, en la que se liga el cambio en la escuela al cambio revolucionario de tipo político, impide toda acción emancipatoria surgida en la escuela, la desmoviliza. Es evidente que esta fase no posibilitaba un desarrollo de la EpP, sobre todo dentro de la escuela, en este contexto ciertamente "sofocante" y bastante pesimista para acciones constructivas. En todo caso se podría hablar de EpP como desvelamiento de la violencia, es decir, una EpP deconstructiva, que se queda en la fase «negativa». El fracaso de la teoría de la reproducción hizo que se abandonara a finales de los setenta con la aparición de la conocida obra de Willis (1977: Aprendiendo a Trabajar), iniciándose así la segunda fase en la tradición crítica.

Segundo perfodo: La teoría de la resistencia o producción cultural (años ochenta). Autores norteamericanos como Giroux, Apple, Popkewitz... han criticado el reduccionismo mecanicista y economicista que hacen de los profesores y alumnado objetos pasivos de las inexorables fuerzas reproductivas. Apple rechazó esta concepción al ser parte del proceso de reproducción ideológica contra el cual queremos luchar (Apple, 1985, 42. Ver también Apple, $1987,83)$. )Se puede pedir más efectividad desde la ideología dominante? Pero al no ser la reproducción un proceso automático, ningún modelo que afirme la unidireccionalidad de los condicionamientos (de la infraestructura económica hacia la superestructura), la ausencia de conflictos y contradicciones base económica-superestructura, nos va a servir. La contestación es esencial a la reproducción. (Apple, 1986 y 1987). Así pues, se admite que la cultura no está determinada por las fuerzas económicas, sino que mantiene una independencia relativa en tanto en cuanto existen espacios de indeterminación, posibilidades de resistencia crítica, de producción cultural contra hegemónica, emancipatoria. Además de los norteamericanos, tenemos la corriente australiana (universidad de Deakin) representada sobre todo por Kemmis, que junto con Carr (Gran Bretaña) plantean una teoría crítica educativa, que se presenta como una alternativa a las concepciones educativas basadas en el positivismo. Dado que la educación no es un hecho natural sino una práctica sociocultural e histórica concreta, tenemos que interpretarla en sus contextos naturales, por lo que el discurso educativo no es un discurso técnico, neutralista, sino lleno de valores. Es un discurso práctico, éticamente informado, que genera un saber acerca de lo que se debería hacer en una particular situación con el fin de dar expresión práctica a valores e ideales educativos compartidos (Carr, 1990, 158-159). Es decir, supone una toma de conciencia frente a los valores violentos de desigualdad e injusticia (EpP), que desvela las posibles deformaciones ideológicas de los agentes educativos, de sus condicionamientos ideológicos, realizada en un ambiente colaborativo, participativo, grupal e igualitario, a fin de que el saber práctico alcanzado se comprometa con una acción transformadora, lo que supone 
instancias normativas (libertad, paz...) que funcionan como modelos o ideales con que comparar y criticar una situación concreta.

A mediados de los ochenta el centro de las contradicciones se desplaza de las clases a los temas de género y raza. Mujeres, trabajadores, minorías étnicas y otros grupos, gracias a su organización y a sus acciones concretas consiguen mejoras significativas en su calidad de vida, lo que demuestra en la práctica la posibilidad real de la EpP como labor de transformación emancipadora de situaciones violentas y no sólo como acción deconstructiva. Se trata de aprovechar las contradicciones del sistema moviéndose estratégicamente en los espacios de indeterminación, lo que conlleva desvelar los conflictos, a fin de progresar en los valores de una cultura de paz. Pero en teoría de la paz, el conflicto es un elemento clave, connatural al ser humano y a sus acciones; no así la violencia, que es aprendizaje social. Por tanto, la teoría educativa crítica, y con ella la EpP, se debe caracterizar por ser dialógica, deliberativa, dialéctica, por su constante interacción con la práctica, guiada por valores/normas, comprometida con la transformación y emancipación personal y social. Como puede verse, la influencia de la obra de Habermas es importante, pues se subraya la posibilidad de la emancipación como acción contra hegemónica dentro del sistema.

Tercer periodo (finales de los ochenta y años noventa): Autocrítica y Diáspora. En esta tercera fase se da una auto evaluación crítica de la propia teoría crítica, revisándose en qué medida los análisis de la tradición crítica han contribuido a la transformación real de las situaciones, de las problemáticas escolares. La feminista E. Ellsworth (1989) es un buen ejemplo de esta crítica a la pedagogía crítica. La autora señala que el discurso crítico con un alto grado de abstracción y racionalismo, con la profusión de términos genéricos que silencian las diferencias reales que se dan en un aula y con su insistencia en teorizar sobre grandes problemáticas sociales en lugar de analizar y trabajar en el entorno inmediato, acaba por silenciar los problemas concretos que se dan en cualquier clase real, cuando este discurso trata de trasladarse a ese ámbito concreto, lo que termina emparentándolo al discurso liberal, pues al silenciar las diferencias, las oprime y, por consiguiente, contribuye a perpetuar las relaciones de dominación en el aula. Otros autores han señalado también esa generalización y abstracción del discurso crítico que le imposibilita para enfocar las situaciones concretas. Esto motivó que en la comentada segunda fase de la tradición crítica se pasara un tanto al otro extremo, al realizarse estudios etnográficos y culturales de la escuela con un gran detalle, que además trataban de imponer orientaciones muy normativas sobre las acciones de los agentes escolares. El normal rechazo que esto produce en los propios docentes impedía su compromiso con acciones más emancipatorias. La revisión autocrítica de Beyer (1988) señala que aunque los análisis críticos realizados, entre otros, por los autores citados en estas fases de la tradición crítica, han sido irremplazables y trascendentales, sin embargo esta literatura no ha acabado de penetrar en las escuelas. Beyer sostiene que esa literatura ha estado preocupada en demasía en plantar cara a la epistemolo- 
gía positivista, buscando otros fundamentos alternativos. Todo esto unido a la propia jerga que la tradición crítica ha ido acumulando y reconstruyendo, ha terminado por no hacerse comprender por los agentes escolares y ha acabado siendo devorada por el propio sistema.

Esta crítica es coincidente con la autocrítica de Catherine Cornbleth (1990) cuando sostiene que la tradición crítica ha mantenido una inadecuada atención a la práctica del currículum, pues debería haber criticado documentos curriculares concretos, tales como libros, planes de estudio... en definitiva, análisis de las prácticas concretas del aula, para así plantear acciones que las cambien. Además, se ha subrayado en exceso los factores socioeconómicos, lo cual es una simplificación de la multidimensionalidad del currículum. Finalmente, se repite la crítica de la distancia entre el discurso crítico, abstracto y con frecuencia difícil, de la práctica, de los que están en la tarea educativa. Eso explica que se haya quedado a menudo en un discurso moral, cerrado, hecho por teóricos para teóricos, de profesores universitarios para profesores universitarios. Un claro ejemplo de este grave problema aparece en todo el movimiento de reconceptualización curricular, ya que, como sostiene Bolívar $(1995,175)$, al acudir a teorías sociales o filosóficas para revitalizar la teoría curricular ha dado -por contrapartida- el empleo de un lenguaje académico y esotérico, propio y específico de las propias $>$ tribus universitarias. El divorcio entre teoría y práctica hace que esta teoría asuma un papel contrario a lo que pretendía: ser un elemento más de dominación para los prácticos que no entienden dicho discurso.

Curriculum Inquiry (vol. 24, n1 2, 1994) tiene una monografía dedicada a "Critical Theory and Cultural Insularity", con textos de diversos autores. Anyon (116), uno de ellos, sostenía que prácticamente el discurso marxista de los años ochenta en educación ha fracasado definitivamente. Así pues, la profunda crisis de la filosofía marxista y de la sociología del currículum y, en general, como acabamos de ver, de los discursos críticos, impele a reorientar dichos discursos. A la EpP apenas se le puede criticar este teoricismo y desapego de la práctica, porque su desarrollo teórico más importante está más ligado a la práctica, proviene de ella, que a esos ambientes, los universitarios, donde tradicionalmente se produce teoría educativa. Pero junto con la crisis de todo este proceso, paralelamente y a la vez en interacción con él, el pensamiento postmoderno está planteando serios retos a la teoría crítica del currículum y esta polémica afecta también de manera muy fundamental a la EpP. Esta tercera fase, pues, se caracteriza por la crisis del movimiento socio crítico y su diáspora hacia posiciones postmodernas, feministas... con análisis micro políticos y genealógicos de las prácticas educativas, o análisis del poder, en lo que se muestra la influencia de Foucault o el deconstructivismo de Derrida, lo que implica toda una renovación de los análisis marxistas. Tras esta crisis de la tradición crítica, una serie de autores se acercaron al postmodernismo cambiando en parte el tradicional discurso crítico en educación, lo que constituye un reto de la postmodernidad a la teoría educativa modernista. 


\subsection{MODERNIDAD, POSTMODERNIDAD Y EpP. RECUPERACIÓN CRÍTICA DE LA CRÍTICA}

El postestructuralismo francés es el que ha divulgado el uso del término "Postmodernidad» que supone ya un problema de definición (Gervilla, 1993, 25-27). En relación con la teoría educativa y la postmodernidad son más conocidos los enfoques deconstruccionista (Derrida) y genealógico (Foucault) de orientación nietzscheana, es decir, la tradición postestructuralista francesa, la tradición hermenéutica (Gadamer y Ricoeur) y el neopragmatismo americano de R. Rorty. El fracaso del mayo francés y de la primavera de Praga, crean en Francia un ambiente de escepticismo respecto de las posibilidades de transformar la sociedad. En este ambiente escéptico surge el postestructuralismo como una crítica, de sorprendente repercusión en el mundo, de los postulados fuertes de la modernidad.

En las posiciones postmodernas hay aspectos recuperables y otros no. En este sentido debemos asumir los innegables valores críticos del postestructuralismo francés, núcleo básico del postmodernismo, de su crítica a la modernidad y a los valores de la Ilustración y no para elegir unos valores frente a otros, sino para propiciar un diálogo, rico, aunque no exento de dificultades, entre ambos mundos. Debemos recuperar de la crítica postmoderna toda esa lectura de la modernidad utilizando la sospecha, la deconstrucción, la arqueología... para señalar todo lo que hay de máscara, de falso, de oculto, de inconsciente, de constrictivo, en los valores de la modernidad, a fin de que esta reconozca su "fantasma», lo que C. Jung llamó la "sombra», lo que ha dejado fuera, lo otro: el cuerpo, las otras culturas, el desorden, el caos, el espíritu, los desposeídos, lo femenino, lo ecológico, las otras formas de conocer... o se presenta sospechosamente bajo tanta mascarada en el carnaval de la modernidad: la democracia, la moral, los valores religiosos, el sujeto humano... La postmodernidad podría ser considerada como un esclarecimiento del inconsciente sociocultural, de la "sombra» que "acompaña» a la modernidad. La "curación» de la modernidad estaría en asumir esas otras realidades extrañas desde las que se ha criticado a la modernidad señalándole sus límites: postmodernidad, feminismo, ecologismo, pacifismo, multiculturalismo, movimiento antiglobalización y de esos universos insólitos para la conciencia occidental que constituye el centro de gran parte de la experiencia espiritual de las culturas indígenas y de los pueblos orientales. Lo que planteo es una recuperación crítica de la crítica a la modernidad mediante una inversión de aquellas tendencias o factores de decadencia que tiran hacia "abajo» de la postmodernidad presentándola como un fenómeno de cansancio, de vejez de la civilización occidental. Es indudable que en gran parte lo es, especialmente si vemos la postmodernidad en su dimensión social.

Otros lenguajes críticos provienen del silencio, del dolor (desde dentro y de fuera de la modernidad): marginados, tercer y cuarto mundo, niños y niñas explotados laboral y sexualmente, militarizados, agonizantes en las hambrunas... de todo hombre y mujer vaciado de su dignidad y tratado como 
una cosa más por el Mercado, ese grito de dolor es la palabra silenciosa e irrefutable ante los límites de lo que la cultura occidental considera propia identidad y lo que enajena fuera de sus fronteras. El encuentro con esos extraños y sus mundos es la crisis profunda en la que se encuentra desde hace unas décadas la modernidad. Sólo hay una salida madura: si se quiere que lo mejor de la modernidad perviva, debe producirse una transformación reconstructiva que le abra a ese mestizaje con lo otro, la eliminación de las máscaras que la crítica le está señalando.

En síntesis, la posición aquí defendida es que, a pesar de las dificultades, debe apoyarse el diálogo entre la modernidad y los movimientos críticos a ella y entre ellos (postmodernidad, feminismo, ecologismo, pacifismo...) eliminando o reconvirtiendo aquellas tendencias (recuperación crítica) que se orienten hacia la decadencia, el antihumanismo.... De esta forma puede propiciarse la emergencia de una cultura nueva, que ya no sería modernista ni postmoderna, sino necesariamente global, en la que se reencuentren las más significativas experiencias humanas de las culturas indígenas, de las orientales y de occidente. La EpP se colocaría en este contexto como un factor crítico de la modernidad y constructivo de esa emergente cultura mundial.

Tanto en el ámbito de las relaciones internacionales como en el de la investigación para la paz también se hace teoría crítica a la Modernidad. Así desde los contextos postmodernos postestructurales podemos citar a Rengger y Hoffman (1992) o al llamado "Grupo del Discurso» de la Universidad de California en San Diego (antropólogos, sociólogos, sociolingüístas, etnometodólogos...) en el marco del Institute on Global Conflict and Cooperation, en donde se trabaja con una crítica radical al pensamiento bajo la influencia, entre otros de Foucault (Skelly, 1995). Se denuncia, desde la metodología deconstructiva, incluso el conocimiento de los estudios de la paz como una forma de poder (cfr. Martínez Guzmán, 1998).

\subsection{LA POSTMODERNIDAD COMO RETO A LA TEORÍA EDUCATIVA MODERNISTA. HACIA UNA SÍNTESIS RECONSTRUCTIVA}

Como dijimos más arriba, después de la crisis de la tradición crítica, una serie de autores, viendo aspectos positivos en la postmodernidad, y en otros movimientos como el feminismo, empiezan a promover cambios en el tradicional discurso crítico (Giroux, McLaren, Popkewitz...) con lo que parte de la teoría crítica en educación asume aspectos del postmodernismo. Otra parte no, como son aquellos que se basan en la teoría comunicativa de Habermas. Con la reconstrucción que supone la recuperación crítica de la postmodernidad a fin de posibilitar un diálogo con la modernidad, se hace más creíble o simplemente más fácil de llevar a cabo la tesis defendida por Giroux $(1992,136)$ cuando afirma que: 
Si el objetivo es que el postmodernismo ofrezca una valiosa contribución al concepto de educación como una forma de política cultural, entonces los educadores deberán combinar sus proposiciones teóricas más significativas con aquellos elementos modernistas estratégicos que contribuyan a una política de democracia radical (...) Lo que se pretende es sostener que el postmodernismo debe extender y ampliar las reivindicaciones más democráticas del modernismo (Cfr. también Giroux, 1998).

El mismo Giroux reconoce que son discursos (el de la postmodernidad y el de la modernidad) «ideológicamente distintos». Sin embargo una relectura crítica de la postmodernidad podría facilitar el acercamiento, que necesariamente tiene que ser crítico. Giroux $(1997,56-57)$ lo entiende con estas palabras:

Esto no supone ni la muerte del modernismo, ni el rechazo superficial de los nuevos discursos de oposición surgidos dentro del postmodernismo y el feminismo, sino una nueva reflexión sobre cómo los aspectos más críticos de estos discursos pueden servir para profundizar las posibilidades democráticas dentro del mismo proyecto modernista. Pues lo que interesa no es simplemente la aparición de un nuevo lenguaje para repensar la tradición modernista, sino también la reconstrucción de los requisitos politicos, culturales y sociales para realizar una concepción radical de ciudadanía y pedagogía.

Aparte de la pop-degradación del postmodernismo y su presentación como moda propagandística por el poder mediático durante más de veinte años, sobre todo en Norteamérica, mas serio es que se rechace la postmodernidad por su carácter nihilista, reaccionario, novedoso, antiintelectualista y como un producto de consumo. Esto es lo que de decadente hay en la postmodernidad. De ahí la necesidad de una reconstrucción crítica, porque no podemos asumir esas tendencias desde el ámbito de la EpP, pero no todo es eso. Existe una postmodernidad crítica.

\subsubsection{Formas alternativas de entender el discurso postmoderno}

Además de las críticas más serias a la postmodernidad (Habermas y otros) hay cierto tipo de críticos que plantean la polémica de forma dualística al autoproclamarse defensores de la libertad, frente a la postmodernidad; esta forma reductiva aparece casi como una cuestión de buenos contra malos, cuando en realidad lo único que muestran es cómo el discurso postmoderno es sacrificado en aras de la ortodoxia y de mentalidades estrechas.

Debe buscarse una aproximación más productiva, entender cómo las ideas postmodernas centrales clarifican que el poder es producido y extendido a 
través de las prácticas culturales que movilizan relaciones múltiples de subordinación. En vez de proclamar el final de la razón, el pensamiento postmoderno cuestiona los límites del proyecto de la racionalidad moderna y sus pretensiones universalistas sobre el progreso, la felicidad y la libertad. En vez de asumir que la postmodernidad ha abandonado el terreno de los valores, parece más útil aceptar su influencia en el análisis de la construcción histórica y relacional de los valores (...). (Giroux, 1994, 104-105).

Estas formas alternativas de entender el discurso postmoderno son en realidad relecturas críticas de dicho discurso a fin de posibilitar relaciones dialécticas entre la postmodernidad y la modernidad en donde todos pueden ganar, en vez de anularse entre sí. Giroux reclama esa sintesis entre las posiciones teóricas más significativas de la postmodernidad, con los valores ilustrados de emancipación, por tanto, con la modernidad. A esta reconstrucción crítica le llama Border Pedagogy (pedagogía de los límites). Este es también el sentir de Apple en las conclusiones de una de sus obras en las que analiza las conexiones entre cultura y poder en educación:

No hay por qué arrojar del tren las teorias postmodernas y postestructurales como alimento escéptico (...) Si se toman en serio (...) nos ofrecen herramientas politicas y analiticas prometedoras. Si (...) se quedan sólo en un plano cínicamente deconstructivo, mi consejo es que las echemos del tren en la próxima estación (Apple, 1996, 152).

Otro de los campos citados en los que recalan de la diáspora de la crisis del movimiento sociocrítico es el movimiento feminista. Interesante, por su novedad, es la aparición de un enfoque feminista de la teoría curricular, también como enfoque crítico de la modernidad. Sus propuestas plantean desde una voz diferente, la de las mujeres, una nueva forma de comprender el currículum. Podemos citar a N. Noddings (1992) entre otras. Desde otra perspectiva, la epistemológica, se ha tratado también de mostrar las diferencias en el modo de conocer entre el varón y la mujer. En este sentido se ha reivindicado una epistemología propia de las mujeres (Greene, 1994, cfr. 423463). The Monist, vol. 47, n1 4, 1994, ha dedicado este número a la epistemología feminista.

También en la teoría de la paz, con evidentes influencias en la EpP, se hace sentir la voz de las mujeres. A finales de los setenta y en los ochenta se dio una extensión a nivel micro, de la paz tanto negativa como positiva, definida hasta entonces especialmente en el nivel macro, viciada por una perspectiva masculino-patriarcal. Análogamente, el concepto de violencia estructural también fue expandido de lo macro hasta incluir las estructuras a nivel personal para así plantear la abolición de esas estructuras tanto macro como micro que dañan a grupos y a individuos (Brock-Utne, Brigitte, 1989,1990). La perspectiva feminista ha subrayado, pues, lo concreto, el nivel micro, junto con lo no organizado para que se complemente con el nivel macro, general 
y abstracto y la característica organizada de la perspectiva masculina (Reardon, Betty, 1993).

La fenomenología, primero unida con el existencialismo y después influida por la hermenéutica (Gadamer y Ricoeur) es, especialmente en esta segunda orientación, la que, como se dijo más arriba, forma parte también del movimiento postmoderno, pues supone una revalorización de lo subjetivo y singular. Frente a la cuantificación y al objetivismo positivista, la fenomenología privilegia la experiencia vivida del mundo, de la realidad, tal como aparece a mi percepción, a mi conciencia. El mundo sólo existe como contenido de mis representaciones mentales. Esta experiencia vivida es válida y fiable. En el campo educativo busca recuperar su cara humana: el aspecto relacional, informal, personal, vivido, frente a lo planificado, formalizado, técnico o el conocimiento como información. Frente a lo lógico-científico recuperamos el relato, la historia contada, como herramienta válida que nos permite acercarnos a las experiencias de los demás, a la comprensión mutua a través del intercambio de narraciones, a la comprensión de la vida social. En esta perspectiva se revaloriza la comprensión de los que participan o viven las diferentes situaciones y las narraciones que ellos hacen de sí mismos. Es una perspectiva interna pues surge desde, en y para los mismos hechos, frente a lo que otros puedan decir sobre ellos. La EpP es particularmente sensible a esta perspectiva humanista, por otra parte tan cercana a la orientación feminista. La EpP, especialmente su práctica, con sus metodologías que buscan integrar la experiencia personal, la vivencia de situaciones experimentadas, preferentemente en grupo, junto con la reflexión sobre las mismas y su comunicación a los demás (método socio afectivo) tiene una larga experiencia en enfoques que se sitúan en lo fenomenológico-hermenéutico. El método socio afectivo es una estrategia metodológica básica en el campo educativo de la paz. La investigación educativa desde esta perspectiva, propia también de la EpP, adopta la forma de racionalidad interpretativa, hermenéutica, naturalista y se expresa como investigación narrativa y biográfica. Su origen es interdisciplinario pues está vinculada a estudios literarios, etnográficos, históricos, culturales, antropológicos, psicológicos... Este giro hermenéutico-narrativo experimentado en las ciencias sociales se corresponde en gran parte con la caracterización que Anyon $(1994,118)$ observa en el movimiento postmoderno:

- La importancia de lo local, de las narrativas locales, frente a las grandes narrativas ilustradas (ejemplo máximo es el discurso marxista). No se pretende una verdad universal más allá de los contextos concretos.

- La validez de la deconstrucción, que busca mostrar las contradicciones, rupturas o inestabilidades de un discurso, revela sus silencios, lo que valora y lo que no (Derrida).

- La centralidad del discurso, pero de un discurso local, en el que los actores adquieren significación a través del lenguaje. Este discurso puede ser liberador, pues al centrarse en lo micro social, puede desve- 
lar las relaciones de poder concretas que se dan en esa situación, frente al discurso abstracto de la pedagogía crítica.

Algunos autores importantes en esta línea son Pinar, Van Manen, Aoki, Grumet, Clandinin, Connelly y discípulos de estos. La orientación más predominante es la fenomenológico-hermenéutica en la línea de Gadamer y Ricoeur que considera las acciones y prácticas educativas como textos a interpretar en su narratividad (Bolívar, 1995, 203), se trata de considerar la acción educativa como un texto que puede ser analizado. Aquí resuena de nuevo la polémica entre Gadamer y Habermas. Este tipo de discurso y de investigación es correcto, pero hay que cuidar de no absolutizar ahora lo concreto, el relato, la interpretación de los protagonistas, lo local. Si antes la preocupación estaba en lo universal, lo necesario, ahora no seamos unilaterales, pero de signo contrario, y veamos sólo lo particular, lo variable y lo contingente, lo cual también sería cuestionable en sus implicaciones prácticas. Ya dijimos que las autoconcepciones de los agentes deberían revisarse para detectar distorsiones ideológicas que obren en contra de instancias normativas como la paz, la justicia, los derechos humanos... La EpP debe estar muy atenta a estos peligros porque afecta a los valores que constituyen el corazón de sus preocupaciones éticas.

\subsubsection{Postmodernidad y educación}

La influencia del postestructuralismo en la educación, como parte importante de la corriente postmoderna se introduce en Norteamérica en los años ochenta, es decir, después que la fenomenología. Los autores inspiradores son fundamentalmente Deleuze, el segundo Foucault (de "Saber y Poder»), Derrida, Serres, Barthes, Lacan. La recepción educativa de estos autores aparece en Cherryholmes, Doll, Daignault, Gauthier, Elbaz, Lather... Se dan combinaciones de todo tipo. Por ejemplo, Lather $(1992,7)$ utiliza una conjunción del feminismo, el neomarxismo y el postestructuralismo. Opta por un discurso posmodernista con influencia de Derrida. Cherryholmes conjuga a Foucault con el deconstruccionismo de Derrida, el neopragmatismo de Rorty y ciertos elementos de Habermas. Hay otros autores como Giroux, McLaren que han tomado algunos elementos del postestructuralismo... y otros han hecho combinaciones aún más brillantes. No se si el campo del currículum se ha revitalizado con esta importación masiva de teorías filosóficas como buscaban los reconceptualistas, pues sino todas, al menos una parte muy significativa de estas teorizaciones pueden acabar en una nueva recaída en el teoricismo, en el lenguaje esotérico y con escasa incidencia en la práctica educativa (Bolivar, 1995, 203-204).

Las posiciones genealógicas y deconstructivas son interesantes, en el ámbito de la EpP, por ser desveladoras de violencia, por ejemplo, en el currículum, en cualquier situación práctica, en consecuencia, sería como el primer paso de un discurso emancipador si luego proponemos acciones de 
mejora. De esta forma recuperaríamos esos discursos con fácil inclinación a quedarse en el estadio meramente "negativo o crítico. En EpP se podrían plantear investigaciones asumiendo estos enfoques. Así, por ejemplo, se podría partir de descripciones narrativas de situaciones problemáticas contadas por los mismos participantes, para alcanzar, en una segunda fase, el desvelamiento de su sintaxis violenta, y acabar finalmente con propuestas de acciones transformadoras. Todo esto supone un reto para la educación, para las escuelas, que son instituciones de la modernidad y que se encuentran inmersas cada vez más en una cultura postmoderna. Estamos ante una generación de jóvenes que está experimentando la vida con un sentido muy diferente de las representaciones ofrecidas por la escuela de la modernidad. Cada vez confían menos en los mapas de la modernidad para construir su vida, pues tienen ante sí un panorama cultural en progresivo proceso de descentramiento y multiplicidad, en el contexto de una poderosa cultura mediática basada en la imagen y en el ordenador, con una vivencia de la indeterminación, de la aleatoriedad, de la fragmentación, de la pérdida de referentes... con un incierto futuro económico. La educación, la EpP, tiene que asumir esta nueva situación y plantearse una pedagogía como práctica cultural crítica (Giroux, 1994, 122).

Giroux (1997, 95-108) sugiere un programa de trabajo de lo que entiende por "pedagogía postmoderna" (que sintetizo como ejemplarización de una forma de entender este diálogo entre modernidad y postmodernidad en relación con la educación y la EpP) que procede de la convergencia de varias tendencias dentro del modernismo, postmodernismo y feminismo postmoderno (...) intento apropiarme críticamente de los aspectos más importantes de dichos movimientos teóricos (...) (Giroux, 1997, 97). Como puede verse a continuación son principios de una Cultura de Paz. Negándose a contraponer entre sí estas tendencias, destaca lo que considera más positivo y característico de cada movimiento: el modernismo subraya la importancia de construir un discurso que sea ético, histórico y político. El postmodernismo está contra los discursos totalizadores, poniendo el énfasis en lo contingente, lo específico y una política de la diferencia, entre otras cosas (cfr. Gervilla, 1993, 36-62). El feminismo postmoderno, que destaca la importancia de basar nuestras visiones en un proyecto político, estrecha la relación entre lo personal (el ser mujer) y lo político como parte de una lucha más amplia por la justicia y la transformación social. Los principios que expone Giroux $(1997,97-105)$ son los siguientes:

1. La educación en las escuelas debe incluir también temas como el poder, la identidad personal, la posibilidad de acción y lucha colectiva... La pedagogía crítica debe vincular la educación pública con los imperativos de una democracia crítica para poder construir las escuelas como esferas públicas democráticas donde se enseñe y practique una ciudadanía crítica.

2. La ética es un tema central de la pedagogía crítica, ética que se muestre como un discurso social que se niegue a aceptar la explotación y el 
sufrimiento humano innecesario; una práctica contra la desigualdad y para extender los derechos humanos básicos.

3. La pedagogía debe centrarse en la cuestión de la diferencia para entender cómo las identidades y las subjetividades de los estudiantes se construyen de modos múltiples y contradictorios en función de razas, géneros, clases... Por otro lado las diferencias entre grupos se desarrollan en estructuras que posibilitan y también impiden las relaciones.

4. La pedagogía crítica no debe reducir las cuestiones de poder, justicia, lucha y desigualdad a un guión simple, a una narrativa maestra que suprima lo contingente, lo cotidiano, lo histórico como objeto digno de estudio.

5. La pedagogía crítica necesita crear nuevas formas de conocimiento mediante su insistencia en romper los límites disciplinares, reivindicándose así, como una política cultural y una forma de memoria social, y no por meras cuestiones epistemológicas, sino éticas, de poder y políticas. En cuanto forma de memoria social parte de lo cotidiano y lo particular como base para el aprendizaje, reivindicando lo histórico y lo popular para recuperar críticamente las voces de quienes han sido silenciados.

6. Es preciso reformular el concepto ilustrado de "razón" dentro de una pedagogía crítica. Es preciso que los educadores sean escépticos respecto a cualquier noción de razón que pretenda revelar la verdad negando su propia construcción histórica y sus principios ideológicos. La razón no es inocente (Giroux, 1997, 101). Es una construcción histórica atravesada por intereses ideológicos. De esta forma el currículum presenta a los estudiantes formas particulares de la razón que estructuran relatos y formas de vida específicos, lo que la hacen estar en la intersección del poder, el conocimiento y la política. La razón debe extenderse incluyendo el reconocimiento de esos otros caminos por los que la gente aprende y adopta posiciones subjetivas particulares, mediante relaciones sociales concretas, mediante la producción e implicación del deseo y el afecto.

7. La pedagogía crítica necesita integrar un lenguaje crítico junto con el de las alternativas, de las posibilidades, que sea capaz de elaborar pensamientos arriesgados, proyectos de esperanza, no como una forma cosificada de utopía, sino como un requisito para alimentar convicciones que tienen el coraje de imaginar un mundo diferente y más justo, y de luchar por él. Un lenguaje que vaya más allá de la desesperación, de la vaciedad apocalíptica y la nostalgia.

8. La pedagogía crítica necesita desarrollar una teoría de los educadores y trabajadores culturales como intelectuales transformativos (Giroux, 
1997, 103). Es preciso que no sólo desenmarañen los códigos ideológicos, representaciones y prácticas que estructuran el orden dominante, sino que también y de forma inseparable se acompañe con la autocrítica. Esta crítica, la resistencia y la transformación se organizan mediante sistemas de conocimiento y redes de solidaridad que abarquen lo local y lo mundial, para compartir identidades y experiencias. Los temas de ecología, militarismo, derechos humanos y otros en donde aparecen la dominación contra las personas y el planeta, nos afectan a todos.

9. La pedagogía crítica debe combinar en su práctica el concepto postmoderno de diferencia con la insistencia feminista en la primacía de lo político, sin reducir esto a lo personal. Así, el yo debe considerarse un primer lugar de politización al plantear las diversas maneras cómo se construye ese yo. Esto supone abordar problemas de historia, cultura, comunidad, lenguaje, género, clase y raza que posibilite y extienda el autoentendimiento de los estudiantes y de los contextos en que viven.

\section{CONCLUSIÓN. HACIA UNA RECONSTRUCCIÓN INTERCULTURAL DE LA PAZ Y DE LA EPP}

En estos puntos aparece claro que la práctica pedagógica no es algo que sólo acontece en las escuelas, sino que se refiere a cómo aprenden los individuos, cómo se construyen las identidades y los posicionamientos subjetivos. La práctica pedagógica hace referencia a formas de producción cultural (Giroux, H. y Mc Laren, P. 1998; Giroux, H. 2001) y estas son históricas, políticas, sociales... La EpP asume estos discursos. La insistencia del liberalismo en la libertad individual, debe integrarse con la inquietud del postmodernismo por lo particular y con la insistencia histórica del socialismo democrático por la solidaridad y la vida pública y la llamada de atención de la ecología por la vida en el planeta, unida a la insistencia del feminismo por la política de lo cotidiano, junto con la importancia dada por la pluriculturalidad a la multitud de culturas y a la enorme riqueza de la experiencia humana acumulada en ellas... Estos discursos, que en sus mutuas relaciones dialécticas ponen freno a sus propios excesos y se complementan en sus silencios, pueden y deben formar una rica complementariedad de perspectivas. He aquí lo que estamos entendiendo como EpP desde una perspectiva crítica, y las múltiples posibilidades de investigación en esta línea. Pero a estos discursos le faltan, en mi opinión, la dimensión interna de la paz, algo bastante alejado de la tradición crítica, aunque no tanto de los propios discursos pluriculturales: el acercamiento a la riqueza que respecto de la paz existen en otras culturas.

Frente al universalismo centralista y expansionista occidental, oponemos el reconocimiento de la diferencia y el diálogo intercultural. No podemos imponer nuestras concepciones, experiencias, procedimientos y prácticas de paz como las únicas. Sería una forma de violencia cultural, pues siendo la 
paz una experiencia plural, ninguna cultura puede pretender que se privilegie la propia experiencia por encima de las demás. En situación de igualdad, consideraremos un privilegio enriquecernos del latido cultural de otros pueblos. Además, sólo nos hacemos conscientes de nuestros «mitos», es decir de nuestro inconsciente cultural, el "color de las gafas" a través de las que miramos y construimos el mundo, cuando nos ponemos en contacto real con otras culturas y sus mitos. Para ello hace falta el diálogo. Y ya sabemos que este no es posible si no es en condiciones de igualdad, lo que supone ofrecimiento de lo propio a la molienda fecunda con los otros. Estas actitudes están más allá de considerar a occidente y, en concreto, a la modernidad, como el molde básico sobre el que refundir las demás culturas.

En el tema de la paz, una cosa es evidente, nos dice Galtung, uno de los principales teóricos de la paz: hay un tesoro oculto en el pensamiento humano de la paz. Nos compete a nosotros desenterrarlo (Galtung, 1985, 102). Pero mientras Occidente enfatiza una planificación extrovertida de la paz (aspectos socioeconómicos y socioculturales) cuyo fin último es la paz para el mundo. El fin último en la planificación introvertida de la paz es la paz en la propia alma, la paz intrapersonal, la armonía espiritual que implica una transformación interior de la persona. Así como la primera puede sobreestimarse en Occidente, la segunda puede sobreestimarse en Oriente (Galtung, 1985,93 ). Por consiguiente, la dimensión interna de la paz debe ser tenida en cuenta, desde una posición de diálogo cultural, lo que supone una reconstrucción intercultural del concepto de paz (Fdez. Herrería, 2003) que de esta forma se enriquece y que propongo se tenga en cuenta como un elemento irrenunciable, junto con los otros discursos que acabamos de indicar, en la comprensión de lo que entendemos por EpP desde una perspectiva crítica. Sin esta dimensión interior, que es el fundamento de toda liberación y cambio real, todo lo expuesto aquí como forma de entender una EpP crítica, puede ser sencillamente utópico si no se liga el cambio exterior con el imprescindible cambio interior de las personas como conversión a la paz. Hay otra parte del discurso crítico actual en educación que no ha asumido principios de la postmodernidad, tal como aquí hemos desarrollado. Es el que se basa en la teoría de la acción comunicativa de Habermas, pero que no podemos ya desarrollar aquí. 


\section{BIBLIOGRAFÍA}

ANYON, J. (1994) The retreat of marxism and socialist feminism: postmodern and poststructural theory in education, en Curriculum Inquiry, 24 (2), pp. 115-133.

APEL, K.-O. (1985) La transformación de la filosofía (Madrid, Taurus, vol. I y II).

APPLE, M. (1985) El marxismo y el estudio reciente de la educación, en Educación y Sociedad, 4.

APPLE, M. (1986) Ideología y currículo (Madrid, Akal).

APPLE, M. (1987) Educación y poder (Madrid, Paidós/MEC).

APPLE, M. (1996) Política cultural y educación (Madrid, Morata).

BEYER, L.E. (1988) La reconstrucción del conocimiento y de los estudios educativos, en Revista de Educación, 286, 129-150.

BOLÍVAR,A. (1995) El conocimiento de la enseñanza. Epistemología de la investigación curricular (Universidad de Granada, FORCE).

BROCK-UTNE, B. (1989) Feminist perspectives on peace and peace education (Oxford, Pergamon Press).

BROCK-UTNE, B. (1990) Feminist perspectives on peace, en SMOKER y otros. A reader in peace studies (Oxford, Pergamon Press).

CARR, W. (1990) Hacia una ciencia crítica de la educación (Barcelona, Laertes).

CARR, W. Y KEMMIS, ST. (1988) Teoria crítica de la enseñanza (Barcelona, Martínez Roca).

CORNBLETH, C. (1990) Curriculum in contex (London, Falmer Press).

ELLIOT, J. (1987, v.c. 1990) Teoría educativa, filosofía práctica e investigación acción, en ELLIOT, J. La investigacción-acción en educación (Madrid, Morata).

ELLSWORTH, E. (1989) Why doesn't this feel empowering. Working throught the repressive myths of critical pedagogy en Harvard Educational Review, 59 (3), pp. 297-324 y vol. 60, pp. 396-405.

FERNÁNDEZ. HERRERÍA, A. (1994) Anotaciones críticas al movi-miento institucional. La cultura de la resistencia en las aulas, en FERNÁNDEZ. HERRERÍA, A. (Ed.) Educando para la paz: Nuevas propuestas (Servicio de Publicaciones de la Universidad de Granada, Colección Eirene).

FERNÁNDEZ. HERRERÍA, A. (2003) Una reconstrucción in-tercultural del concepto de paz, en LÓPEZ-BARAJAS, E. y BOUCHE PERIS, H (Coords) La educación para una cultura de paz: problemas y perspectivas (Madrid, UNED).

GALTUNG, J. (1985) Sobre la paz (Barcelona, Fontamara).

GERVILLA, E. (1993) Postmodernidad y educación (Madrid, Dykinson).

GIROUX, H. (1992) La pedagogía de los límites y la política del postmodernis$m o$, en GIROUX y FLECHA. Igualdad educativa y diferencia cultural (Barcelona, El Roure).

GIROUX, H. (1997) Cruzando límites. Trabajadores culturales y políticas educativas. (Barcelona, Paidós).

GIRUOX, H. (1994) Jóvenes, diferencia y educación postmoderna, en CASTELL, FLECHA, FREIRE, GIROUX y otros Nuevas perspectivas críticas en educación (Barcelona, Paidós). GIROUX, H y MCLAREN, P. (1998) Sociedad, cultura y educación (Madrid, Mino y Dávila editores).

GIROUX, H. (2001) Cultura, politica y práctica educativa (Barcelona, Graó).

GIROUX, H. (1998) La escuela y la lucha por la ciudadania: pedagogía crítica de la época moderna (México, siglo XXI).

GREENE, M. (1994) Epistemology and Educational Research: The Influence of Recent Approaches to Knowledge, en Review of Research in Education, 20, pp. 423-463. 
LATHER, P. (1992) El postmodernismo y las políticas de ilustración, en Revista de Educación, 297, pp. 7-24.

MARTÍNEZ GUZMÁN, V. (1998) Paz, en CORTINA, A. (ed) Diez palabras clave de Filosofía Política (Estella, Verbo Divino).

NODDINGS, N. (1992). Gender and the curriculum en PH. JACKSON (ed.) Handboock of research on curriculum (N. York, Macmillan).

PINAR, W.F. y BOWERS, C.A. (1992) Politics of Curriculum: Origins, Controversies, and Significance of Critical Perspectives, en Review of Research in Education, 18, pp. 163-190.
REARDON, B. (1993) Women and peace. Feminist visions of global security (Albany, State University of New York press).

RENGGER, N. y M. HOFFMAN (1992) Modernity, Postmoder-nism and International Relations, en DOHERTY, J. y otros (eds) Postmodernism and the Social Sciences (London, McMillan).

SKELLY, J. M. (1995) Cultura, paz y comunicación, en MARTÍNEZ GUZMÁN, V. (ed) Teoría de la paz (Valencia, Nau Llibres).

VATTIMO, G. (1987) El fin de la modernidad. Nihilismo y hermenéutica en la cultura posmodema (Barcelona, Gedisa).

\section{RESUMEN}

Este artículo se plantea qué podemos entender hoy por educación para la paz desde una perspectiva crítica. Para ello se recorren los procesos que han afectado a la corriente crítica: $1 .^{\circ}$, su polémica con la hermenéutica, en la que más allá de la oposición se reconoce la necesaria complementariedad entre ambas; en 2. ${ }^{\circ}$ lugar, la crisis de la corriente critica y su diáspora hacia posiciones postmodernas, feministas, pacifistas... lo que plantea situar a la educación para la paz en todas estas vicisitudes, en un diálogo con la modernidad y la postmodernidad, que aporta enriquecimiento a la educación para la paz y alejamiento de posiciones simplificadoras.

Palabras clave: educación para la paz, modernidad, postmodernidad, perspectiva crítica.

\section{ABSTRACT}

This article conducts a critical study of the concept of educating for peace. It covers the various developments that have affected the critical approach: First, its relationship with hermeneutics, which should go beyond opposition and recognise the crucial complementariness of both disciplines. Second, the crisis of the critical approach and its flight towards postmodernist, feminist and 
pacifist stances which necessarily require the adaptation of educating for peace within a dialogue with modernity and post-modernity that will have an enriching contribution to make and will help avoid over-simplifying stances.

Key words: educating for peace, modernity, post-modernity, critical approach. 